\title{
Effect of Coronavirus Disease-2019 Pandemic on the Sleep Quality of Indian Population
}

\author{
Shweta Kanchan ${ }^{1}$, Krishna Kant Bhardwaj ${ }^{2}$, Sunita Tiwari ${ }^{3}$, Siddhant Bakshi ${ }^{4}$, Prashant Vajpei ${ }^{5}$
}

\begin{abstract}
Aim and objective: This survey was conducted to compare the sleep quality of the general Indian population before the coronavirus disease2019 (COVID-19) pandemic and during the pandemic using Pittsburgh Sleep Quality Index (PSQI).

Materials and methods: It is a cross-sectional online survey-based study conducted on 1,000 consenting Indian adult citizens. The survey was circulated by the investigators through an online link on various social media platforms. It had questions based on PSQI to access the sleep quality. Results: The mean PSQI before the pandemic was found to be 4.37 and during the pandemic to be 5.00. Results showed that the pandemic had deteriorated the sleep quality of general population of India. All the sleep parameters in the PSQI scale showed deterioration in sleep quality due to the pandemic. Significant change was seen in the level of enthusiasm-34.3\% people lacked the enthusiasm to get the things performed before the pandemic while $48.4 \%$ people lacked the enthusiasm to get the things performed during the pandemic.

Conclusion: The study indicated a marked decrease in the sleep quality during the pandemic as compared to before the pandemic.

Clinical significance: This survey informs about the change in sleep quality parameters due to COVID-19 pandemic.

Keywords: Pandemic, Pittsburgh sleep quality index, Sleep quality.

Indian Journal of Sleep Medicine (2020): 10.5005/jp-journals-10069-0055
\end{abstract}

\section{INTRODUCTION}

The spread of the coronavirus disease-2019 (COVID-19) pandemic in India has led people to spend maximum time indoors to prevent from the coronavirus infection. ${ }^{1}$ This self-imposed confinement is being witnessed for the first time in history and has led to stress, anxiety, physical inactivity, and sleep disturbances. ${ }^{2}$ The reasons for sleep disturbances are due to increased mental stress as a result of an unprecedented change in lifestyle due to the pandemic, the financial insecurities, and the fear of catching disease. ${ }^{3}$ Pandemic led sleep disturbance can manifest as insomnia, delayed bed time or extended time in bed, ${ }^{4}$ sleep disturbances for months during the pandemic can lead to long-term consequences like circadian desynchrony, ${ }^{5}$ depression, or metabolic disturbances. Sleep quality has degraded during isolation also due to disturbed sleep-wake cycles and light exposure. ${ }^{6}$ The present pandemic has affected sleep, this study was performed to determine the degree to which the different sleep quality parameters based on the Pittsburgh Sleep Quality Index (PSQI) have deranged due to the pandemic in the general Indian population, compared to the sleep parameters before the pandemic started.

\section{Materials and Methods}

The survey was conducted through an online questionnaire having nine multiple choice question-based items, pertaining to various sleep quality indices based on the PSQI which is used to access the quality of sleep over a month. The participants were asked questions for two situations. First, for the 1 month just before the pandemic (based on memory) and second, for the first 1 month of pandemic during which the survey was carried out. The questionnaire was circulated by the investigators through an online link on various social media platforms like WhatsApp, Facebook, Instagram, and Gmail. A note was shared alongside the questionnaire mentioning
${ }^{1-4}$ Department of Physiology, King George's Medical University, Lucknow, Uttar Pradesh, India

${ }^{5}$ Department of Biostatistics, Abbot Health Care, Lucknow, Uttar Pradesh, India

Corresponding Author: Shweta Kanchan, Department of Physiology, King George's Medical University, Lucknow, Uttar Pradesh, India, Phone: +918808390589, e-mail: drshwetakanchan@ gmail.com

How to cite this article: Kanchan S, Bhardwaj KK, Tiwari S, et al. Effect of Coronavirus Disease-2019 Pandemic on the Sleep Quality of Indian Population. Indian J Sleep Med 2020;15(3):35-38.

Source of support: Nil

Conflict of interest: None

the exclusion criteria for study to prevent people from the excluded category from filling the survey. Ethical clearance was obtained before circulating the survey. Snowball sampling method was followed to collect maximum responses. The online link opened up with the question asking consent to participate in the survey. One thousand and eighteen people participated in the survey of which 1,000 responses were valid and included in the study. The data were collected for 2 weeks' time period and after that detailed statistical analysis was carried out to find the changes in the sleep quality indices due to the pandemic.

\section{Inclusion Criterion}

All adult Indian citizens who were literate.

\section{Exclusion Criterion}

People with any chronic disease like asthma, diabetes, mental disorders, taking medication affecting sleep.

() The Author(s). 2020 Open Access This article is distributed under the terms of the Creative Commons Attribution 4.0 International License (https://creativecommons. org/licenses/by-nc/4.0/), which permits unrestricted use, distribution, and non-commercial reproduction in any medium, provided you give appropriate credit to the original author(s) and the source, provide a link to the Creative Commons license, and indicate if changes were made. The Creative Commons Public Domain Dedication waiver (http://creativecommons.org/publicdomain/zero/1.0/) applies to the data made available in this article, unless otherwise stated. 


\section{Results}

A research was conducted to evaluate the variation in sleep pattern and quality of the subjects during the pandemic as compared to sleep quality before the pandemic. Data of 1,000 respondents were analyzed, out of which 547 were males and 453 were females. The mean $( \pm S D)$ age was reported as $27.46( \pm 12.42)$ years (Table 1$)$.

Sleep pattern of the subjects was assessed using "How long (in minutes) has it taken you to fall asleep each night" and "How many hours of actual sleep do you get at night" before and during the pandemic. Summary statistics were evaluated for all the subjects for the respective variables and categories. Furthermore, the difference was assessed using the paired $t$ test at $5 \%$ level of significance. The sleep onset latency increased significantly by about 9 minutes ( $p$ value $<0.0001$ ). Standard PSQI scale was used to assess the sleep quality of the subjects before and during the pandemic. Furthermore, based on the responses received from the subjects, "Global Pittsburgh Sleep Quality Index Score" was evaluated for all subjects before the pandemic and during the pandemic. Mean $( \pm$ SD) PSQI score during the pandemic was reported as $5.00 \pm 2.73$ with $95 \% \mathrm{Cl}$ as $(4.83,5.17)$, further mean $( \pm \mathrm{SD}) \mathrm{PSQI}$ score before the pandemic was reported as $4.37 \pm 2.50$ with $95 \% \mathrm{Cl}$ as $(4.22$, 4.53) (Tables 2 and 3).

There was no significant change in sleep quality due to engagement in any social activities. People having problem in keeping up enthusiasm to get the things done increased from $34.3 \%$ (before pandemic) to $48.4 \%$ (during pandemic). This was found to be a major reason affecting the sleep quality. Most of the people self-rated their sleep quality as fairly good or very good but it also decreased by $2.4 \%$, i.e., from $86.3 \%$ (before pandemic) to $83.9 \%$ (during pandemic). $30.9 \%$ of the people who did not nap (daytime sleep) started napping during the pandemic. While people with increased napping time (in whom napping was present both before and during the pandemic) was found to be $39.6 \%$. Majority of the population (75.2\%) wanted an "off" like this lockdown but almost half of the population (51.8\%) did not want it to be this much long.

\section{Discussion}

The global PSQI score was found to increase during the pandemic in comparison to before the pandemic which shows that the sleep quality has deteriorated. This result was similar to a recent study conducted by Ravi et al. ${ }^{7}$ in Indian population during COVID-19 pandemic which showed a decrease in sleep quality during the pandemic. The present study shows a decrease in total sleep time which may be due to a decreased homeostatic

Table 1: Summary statistics for demographics

\begin{tabular}{lll}
\hline Variable & Statistics & \\
\hline Age & $N$ & 1,000 \\
& Mean & 27.46 \\
& SD & 12.42 \\
& Median & 21.00 \\
& SE & 0.39 \\
\hline Gender & Category & $n(\%)$ \\
\hline \multirow{2}{*}{ Residence } & Male & $547(54.7)$ \\
& Female & $453(45.3)$ \\
& Rural & $187(18.7)$ \\
\hline
\end{tabular}

drive to sleep because of restriction of movement and decrease in physical activity. ${ }^{8}$ Living in social isolation creates a feeling of loneliness ${ }^{9}$ which develops anxiety ${ }^{10}$ and stress, and all these conditions degrade our sleep quality. ${ }^{11}$ In the previous studies, it had been reported that women in prisons commonly have insomnia disorders ${ }^{12}$ and are poor sleepers. ${ }^{13}$ This may be the reason for decreased total sleep time and increased number of awakenings during the present pandemic where people have to stay in social isolation. A recent study by Nicola Cellini et al. ${ }^{14}$ observed that non-hospitalized residents $<35$ years of age, going to bed and waking up late, and spending more time in bed had lowered sleep quality. However, the present study observed that the major factor found to affect the sleep quality was lack of enthusiasm to get the things done, there was a decrease of nearly $15 \%$ in the enthusiasm level during the pandemic time compared to pre pandemic time. Deteriorated sleep quality may affect the efficiency with which a person does his day-to-day work. Furthermore, it may also reduce the immunity ${ }^{15}$ which makes us more susceptible to attack by the COVID-19 pandemic. The levels of social isolation may also affect the sleep quality up to varying degrees, ${ }^{16}$ thus the decrease in sleep quality would be subject to the extent of pandemic in an area, government restrictions on socialization, and extent of following social isolation by individuals themselves. Our study had mostly youth as respondents, mean age 27.4 and SD of 12.4, and therefore the results are a more reflective of younger generation. A survey on the effect of COVID-19 on the sleep quality stratified across different age groups could further elaborate the knowledge.

\section{Conclusion}

The above reported data clearly denote that the sleep quality of subjects worsened during the pandemic as compared to the

Table 2: Sleep latency and global mean Pittsburgh Sleep Quality Index (PSQI) scale

\begin{tabular}{lllll}
\hline & & $\begin{array}{l}\text { Before } \\
\text { pandemic }\end{array}$ & $\begin{array}{l}\text { During } \\
\text { pandemic }\end{array}$ & $\begin{array}{l}\text { Mean } \\
\text { difference }\end{array}$ \\
\hline How long (in min- & $n$ & 1,000 & 1,000 & 1,000 \\
utes) has it taken & Mean & 35.8 & 45.17 & 9.37 \\
you to fall asleep & SD & 81.47 & 92.1 & 40.88 \\
each night? & SE & 2.58 & 2.91 & 1.29 \\
& $95 \% \mathrm{Cl}$ & - & - & $(6.83,11.91$ ) \\
How many hours & $p$ value & - & - & $<0.0001$ \\
of actual sleep do & Mean & 1,000 & 1,000 & 1,000 \\
you get at night? & SD & 34.36 & 7.45 & -1.91 \\
& SE & 1.09 & 15.03 & 37.59 \\
& $95 \% \mathrm{Cl}$ & - & 0.48 & 1.19 \\
& & & - & $(-4.24$, \\
& $p$ value & - & - & $0.42)$ \\
Global mean PSQI & $n$ & 1,000 & 1,000 & 0.1080 \\
& Mean & 4.37 & 5.00 & 0.63 \\
& SD & 2.50 & 2.73 & 1.99 \\
& SE & 0.08 & 0.09 & 0.06 \\
& $95 \% \mathrm{Cl}$ & $(4.22,4.53)$ & $(4.83$, & $(0.504$, \\
& & & $5.17)$ & $0.752)$ \\
& $p$ value & - & - & $<0.0001^{*}$ \\
\hline
\end{tabular}

${ }^{*} p$ value and $95 \% \mathrm{Cl}$ have been evaluated using paired $t$ test at $5 \%$ level of significance 
Table 3: Comparing sleep indices before and during pandemic

\begin{tabular}{|c|c|c|}
\hline & $\begin{array}{l}\text { Before pandemic } \\
(n=1,000)\end{array}$ & $\begin{array}{l}\text { During pandemic } \\
(n=1,000)\end{array}$ \\
\hline $\begin{array}{l}\text { People who had troubled } \\
\text { sleeping because they } \\
\text { could not get to sleep } \\
\text { within } 30 \text { minutes, three } \\
\text { or more times a week. }\end{array}$ & $8 \%(80)$ & $\begin{array}{l}19.9 \% \text { (199) (more } \\
\text { than doubled) }\end{array}$ \\
\hline $\begin{array}{l}\text { People who had troubled } \\
\text { sleeping because they } \\
\text { woke up in the night or } \\
\text { early in the morning, } \\
\text { three or more times a } \\
\text { week. }\end{array}$ & $7.6 \%(76)$ & $\begin{array}{l}16.2 \%(162) \text { (more } \\
\text { than doubled) }\end{array}$ \\
\hline $\begin{array}{l}\text { People who had troubled } \\
\text { sleeping because they } \\
\text { had to get up to use the } \\
\text { bathroom, three or more } \\
\text { times a week. }\end{array}$ & $8.2 \%(82)$ & $14.7 \%(147)$ \\
\hline $\begin{array}{l}\text { People who had troubled } \\
\text { sleeping because they } \\
\text { could not breathe com- } \\
\text { fortably (though majority } \\
\text { of the population did not } \\
\text { face this problem). }\end{array}$ & $9.7 \%(97)$ & $12.1 \%(121)$ \\
\hline $\begin{array}{l}\text { People who had troubled } \\
\text { sleeping because they } \\
\text { cough or snore loudly, } \\
\text { three or more times a } \\
\text { week. }\end{array}$ & $1.8 \%(18)$ & $2.3 \%(23)$ \\
\hline $\begin{array}{l}\text { People who had troubled } \\
\text { sleeping because they } \\
\text { feel too cold. }\end{array}$ & $14.5 \%(145)$ & $16.3 \%(163)$ \\
\hline $\begin{array}{l}\text { People who had troubled } \\
\text { sleeping because they } \\
\text { feel too hot. }\end{array}$ & $18.2 \%(182)$ & $26.8 \%(268)$ \\
\hline $\begin{array}{l}\text { People who had troubled } \\
\text { sleeping because they } \\
\text { had bad dreams. }\end{array}$ & $35 \%(35)$ & $44.5 \%(445)$ \\
\hline $\begin{array}{l}\text { Number of persons who } \\
\text { had troubled sleeping } \\
\text { because they had pain. }\end{array}$ & $22.7 \%(227)$ & $27.8 \%(278)$ \\
\hline $\begin{array}{l}\text { Number of persons who } \\
\text { had troubled sleeping } \\
\text { because of some } \\
\text { unknown reasons. }\end{array}$ & $18.1 \%(181)$ & $25.3 \%(253)$ \\
\hline $\begin{array}{l}\text { Number of persons who } \\
\text { took medication for } \\
\text { sleeping (though majority } \\
\text { of them were not on any } \\
\text { medication for sleeping). }\end{array}$ & $10.8 \%(108)$ & $\begin{array}{l}8.2 \%(82) \text { (decreased } \\
\text { by } 2.6 \%)\end{array}$ \\
\hline
\end{tabular}

scenario before the pandemic. In order to assess difference between the PSQI scores of subjects before and during the pandemic, paired $t$ test was used at $5 \%$ level of significance, mean $( \pm S D)$ of the mean difference in PSQI, i.e., "Global Pittsburgh Sleep Quality Index during pandemic vs. Global Pittsburgh Sleep Quality Index before pandemic" has been reported as $0.63 \pm 1.99$ with $95 \% \mathrm{Cl}$ as $(0.504$, 0.752 ) and $p$ value as $<0.0001$, which clearly indicates that there is statistically significant difference between "Global Pittsburgh
Sleep Quality Index during pandemic and Global Pittsburgh Sleep Quality Index before pandemic".

\section{Clinical Significance}

The present study gives an insight into the effect of pandemic led psychosocial scenario on the various parameters of sleep quality. It shows a significant decrease in the enthusiasm level to get things done among general population, which has adversely affected sleep. It would do well to have a target-based approach and people should be encouraged to set achievable goals even during the present pandemic, thereby improving their motivation level which will positively influence sleep.

\section{References}

1. Buysse DJ, Reynolds 3rd CF, Monk TH, et al. The Pittsburgh Sleep Quality Index: a new instrument for psychiatric practice and research. Psychiatry Res 1989;28(2):193-213. DOI: 10.1016/0165-1781(89)900474. https://pubmed.ncbi.nlm.nih.gov/2748771/.

2. Odriozola-González P, Planchuelo-Gómez Á, Irurtia MJ, et al. Psychological effects of the COVID-19 outbreak and lockdown among students and workers of a spanish university. Psychiatry Res 2020;290:113108 https://pubmed.ncbi.nlm.nih.gov/ 32450409\%.

3. Morin CM, Carrier J. The acute effects of the COVID-19 pandemic on insomnia and psychological symptoms. Sleep Med 2020. DOI: 10.1016/j.sleep.2020.06.005. https://www.ncbi.nlm.nih.gov/pmc/ articles/PMC7274952/.

4. Marelli S, Castelnuovo A, Somma A, et al. Impact of COVID-19 lockdown on sleep quality in university students and administration staff. J Neurol 2020. 1-8. DOI: 10.1007/s00415-020-10056-6. https:// www.ncbi.nlm.nih.gov/pmc/articles/PMC7353829/.

5. Leone MJ, Sigman M, Golombek DA. Effects of social isolation on human sleep and chronotype during the COVID-19 pandemic. Curr Biol 2020;30(16):R930-R993. Available at SSRN: https://ssrn.com/ abstract=3624469 10.1016/j.cub.2020.07.015.

6. Hartley S, Colas des Francs C, Aussert F, et al. The effects of quarantine for SARS-CoV-2 on sleep: an online survey. Encephale 2020;46(3S):S53-S59. DOI: 10.1016/j.encep.2020.05.003. https:// pubmed.ncbi.nlm.nih.gov/32475692/.

7. Ravi G, Grover S, Basu A, et al. Changes in sleep pattern and sleep quality during COVID-19 lockdown. Indian J Psychiatry 2020;62(4): 370-378. DOI: 10.4103/psychiatry.IndianJPsychiatry_523_20.

8. Kurose S, Miyauchi T, Yamashita R, et al. Association of locomotive activity with sleep latency and cognitive function of elderly patients with cardiovascular disease in the maintenance phase of cardiac rehabilitation. J Cardiol 2019;73(6):530-535. DOI: 10.1016/ j.jjcc.2018.12.015. https://pubmed.ncbi.nlm.nih.gov/30611685/.

9. McHugh JE, Lawlor BA. Perceived stress mediates the relationship between emotional loneliness and sleep quality over time in older adults. Br J Health Psychol 2013;18(3):546-555. DOI: 10.1111/j.2044-8287.2012.02101.x. https://pubmed.ncbi.nlm.nih.gov/ 22988915/.

10. Elger BS. Prevalence, types and possible causes of insomnia in a swiss remand prison. Eur J Epidemiol 2004;19(7):665-677. DOI: 10.1023/B:EJEP.0000036805.58237.e3. https://pubmed.ncbi.nlm.nih. gov/15461198/.

11. Kurina LM, Knutson KL, Hawkley LC, et al. Loneliness is associated with sleep fragmentation in a communal society. Sleep 2011;34(11): 1519-1526. DOI: 10.5665/sleep.1390. https://pubmed.ncbi.nlm.nih. gov/22043123/.

12. Dewa LH, Hassan L, Shaw JJ, et al. Trouble sleeping inside: a crosssectional study of the prevalence and associated risk factors of insomnia in adult prison populations in England. Sleep Med 2017;32:129-136. DOI: 10.1016/j.sleep.2016.12.018. https://pubmed. ncbi.nlm.nih.gov/28366324/. 
13. Harner HM, Budescu M. Sleep quality and risk for sleep apnea in incarcerated women. Nurs Res 2014;63(3):158-169. DOI: 10.1097/ NNR.0000000000000031. https://www.ncbi.nlm.nih.gov/pmc/ articles/PMC4381275/.

14. Cellini N, Canale N, Mioni G, et al. Changes in sleep pattern, sense of time and digital media use during COVID-19 lockdown in Italy. J Sleep Res 2020. e13074. DOI: 10.1111/jsr.13074. https://www.ncbi.nlm. nih.gov/pmc/articles/PMC7235482/.
15. Doherty R, Madigan S, Warrington $G$, et al. Sleep and nutrition interactions: implications for athletes. Nutrients 2019;11(4):822. DOI: 10.3390/nu11040822. https://pubmed.ncbi.nlm.nih.gov/30979048/.

16. Xia $H$, Zhang $Y$, Kong $D$, et al. Social capital and sleep quality in individuals who self-isolated for 14 days during the coronavirus disease 2019 (COVID-19) outbreak in January 2020 in China. Med Sci Monit 2020;26:e923921. DOI: 10.12659/MSM.923921. https://pubmed. ncbi.nlm.nih.gov/32194290/. 